\title{
EXPLORING THE INTERRELATIONSHIP BETWEEN ELECTROLYTES, ANEMIA, AND GLYCOSYLATED HEMOGLOBIN (HBA1C) LEVELS IN TYPE 2 DIABETICS
}

\author{
LAVANYA RAJAGOPAL ${ }^{1 *}$, VINOTHKUMAR GANESAN ${ }^{2}$, SALEH MOHAMMED ABDULLAH ${ }^{3}$, \\ SUNDARAM ARUNACHALAM ${ }^{1}$, KUMARESAN KATHAMUTHU ${ }^{4}$, BALAJI RAMRAJ ${ }^{5}$
}

${ }^{1}$ Department of Pathology, SRM Medical College Hospital and Research Centre, Kattankulathur, Chennai, Tamil Nadu, India. ${ }^{2}$ Department of Medical Research, SRM Medical College, Hospital and Research Centre, Kattankulathur, Chennai, Tamil Nadu, India. ${ }^{3}$ Department of Medical Laboratory, Faculty of Applied Medical Sciences, Jazan University, Jazan, Saudi Arabia. ${ }^{4}$ Department of Pathology, Jazan University, Jazan, Saudi Arabia. ${ }^{5}$ Department of Community Medicine, SRM Medical College Hospital and Research Centre, Kattanulathur, Chennai, Tamil Nadu, India. Email: drrlavan@yahoo.co.in

Received: 12 September 2017, Revised and Accepted: 13 October 2017

ABSTRACT

Objective: The aim of this study is to analyze the interrelationship and pattern of electrolyte imbalance and compare the correlation between serum electrolytes, glycosylated hemoglobin (HbA1C), and hemoglobin ( $\mathrm{Hb}$ ) levels between Type 2 diabetic patients and non-diabetic subjects.

Methods: This study was conducted in 300 subjects (150 diabetics and 150 non-diabetics) and further categorized as anemic and non-anemic within each group. Blood samples were analyzed for HbA1C, hemoglobin, and serum electrolyte levels.

Results: Sodium $\left(\mathrm{Na}^{+}\right)$levels in diabetics were significantly lower and potassium $\left(\mathrm{K}^{+}\right)$as well as chloride $\left(\mathrm{Cl}^{-}\right)$levels were significantly higher, when compared with non-diabetics. A significant positive correlation between $\mathrm{HbA1C}$ and potassium as well as chloride levels in contrast to negative correlation with sodium levels was observed in both genders. Among diabetics with anemia, we found significantly lower sodium and higher potassium and chloride.

Conclusion: In diabetics, levels of sodium were significantly lower, and potassium as well as chloride was significantly higher when compared with non-diabetics. Our study clearly demonstrates an association between electrolytes, hemoglobin, and HbA1C levels in diabetes. This insight should pave the way for pathophysiology-directed therapy, thus contributing to the avoidance of several deleterious effects associated with electrolyte disorders and their treatment.

Keywords: Diabetes, HbA1C, Electrolytes, Anemia.

(c) 2018 The Authors. Published by Innovare Academic Sciences Pvt Ltd. This is an open access article under the CC BY license (http://creativecommons. org/licenses/by/4. 0/) DOI: http://dx.doi.org/10.22159/ajpcr.2018.v11i1.22533

\section{INTRODUCTION}

Diabetes mellitus (DM) is a hereditary chronic and endocrine metabolic disorder associated with hyperglycemia characterized by both insulin resistance and defective insulin secretion [1]. Glycosylated hemoglobin (HbA1C) is used as a gold standard for monitoring the glycemic status for the previous 3 months. The American Diabetes Association (ADA) guidelines have not only considered it as the primary target for glycemic control but also endorsed it as a diagnostic criterion for DM [2]. $\mathrm{HbA}_{1} \mathrm{C}$ has been postulated as a biochemical model for the pathogenesis of diabetic sequelae through the glycosylation reactions.

Electrolyte (sodium $\left(\mathrm{Na}^{+}\right)$, potassium $\left(\mathrm{K}^{+}\right)$, chloride $\left(\mathrm{Cl}^{-}\right)$and bicarbonate $\left(\mathrm{HCO}_{3}^{-}\right)$] balance plays an key role in maintaining the homeostasis in the body and also in protecting cellular function, tissue perfusion, and acid-base balance. Diabetic patients frequently develop a constellation of electrolyte disorders. Hyperglycemia in DM sets the internal environment for osmotic diuresis while causing a dilutional effect on electrolyte concentration. Many research studies have revealed that osmotic effect of glucose results in reduced circulating blood volume and fluid shift from the intracellular spaces causing cellular dehydration. Insulin alters serum sodium and extracellular potassium concentration as well, likely through activation of $\mathrm{Na}^{+}-\mathrm{K}^{+}$-ATPase [3]. In DM, the synergistic action of cationic imbalance and osmotic effect of glucose, altering distribution of sodium $\left(\mathrm{Na}^{+}\right)$and potassium $\left(\mathrm{K}^{+}\right)$ between the intracellular and extracellular compartments, could very well influence the course of the disease as well as its management [4].
Factors such as impaired renal function, dehydration, malabsorption syndromes, acid-base disorders, and multidrug regimens have also been suggested as one of the contributing factors for increased frequency of electrolyte abnormalities in DM [5].

Anemia is a serious public health problem affecting both developing and developed countries, with major consequences on human health as well as social and economic development [6]. Prevalence of anemia in patients with diabetes is estimated about $10-30 \%$ [7]. Several studies proposed that anemia is twice common in diabetics when compared with nondiabetics [8]. The etiology of anemia in diabetes is multifactorial and includes inflammation, drugs, nutritional deficiency, kidney disease, and concomitant autoimmune disorders. Tannen suggested that in anemia, the activity of membrane-bound Na+-K+-ATPase is altered, and due to these, serum $\mathrm{Na}^{+}$and $\mathrm{K}^{+}$levels are also affected [9].

The association between blood glucose and electrolytes is complex, and electrolyte imbalance may affect the course of DM and its management, due to which special interest is centered on their relationship. To the best of our knowledge, only a few studies have been performed so far to identify the interrelationship between serum electrolytes in diabetic patients but with controversial results. Till now, no other studies except ours have correlated the serum electrolytes, HbA1C with anemia in Diabetic patients. Hence in the present study, we aimed to analyze and compare the correlation between serum electrolytes, glycosylated hemoglobin $(\mathrm{HbA1C})$, and hemoglobin $(\mathrm{Hb})$ levels between Type 2 diabetic patients and non-diabetic subjects. 


\section{METHODS}

This is a descriptive analytical cross-sectional study carried out in SRM Medical College Hospital and Research Centre, Chennai, from September 2016 to June 2017 after obtaining approval from our institutional ethical committee. All Type 2 diabetic patients as per the ADA diagnostic criteria were selected from both outpatient and inpatient departments of our hospital and included in the study evaluation. An informed consent was obtained from all the subjects. Detailed medical history recorded.

A total of 300 subjects aged $>18$ years $(150$ diabetics and 150 nondiabetics) were enrolled in our study which comprises 180 males and 120 females. The study subjects were further categorized as those with anemia and without anemia in each group. The anemic patients were selected based on their hemoglobin levels $(\mathrm{Hb}<13 \mathrm{~g} \%$ in males and $<12 \mathrm{~g} \%$ in females) based on definition of the World Health Organization. Blood samples were analyzed for HbA1C, hemoglobin, and serum electrolyte levels.

Patients with Type 1 DM, acute complications such as severe infection, major operations, trauma, GIT disorders, severe cardiovascular/ respiratory diseases, pregnant women, and those with renal disorders were excluded from this study.

Blood samples collected from each subject in dipotassium EDTA tubes were analyzed for glycated hemoglobin (HbA1C) by high-performance liquid chromatography method using Bio-Rad D10 analyzer. Serum analysis for electrolytes was performed by ISE-Direct method using Medica EasyLyte automatic analyzer. Hemoglobin was estimated by SYSMEX XT-1800i analyzer.

\section{Statistical analysis}

The data were analyzed using SPSS version 20 and presented as mean \pm SEM for continuous variables. A student $t$-test was applied for comparison of group means. Pearson's coefficient was calculated to determine the correlation between two variables. $\mathrm{p}<0.05$ was considered statistically significant.

\section{RESULTS}

In the present study, the mean value of $\mathrm{HbA1C} \%$ in diabetics and non-diabetics was $10.82 \pm 0.19$ and $5.94 \pm 0.05$, respectively, and the difference was statistically significant $(\mathrm{p}=0.0001)$. Serum sodium levels in diabetic patients were found to be significantly lower $(p=0.0001)$, and serum potassium and chloride levels were significantly higher $(p=0.0001)$ in diabetic patients compared with non-diabetics. We found that the bicarbonate levels were not altered between diabetics and nondiabetics.

Our study included 180 males and 120 females. We found a significant negative correlation between $\mathrm{HbA1C}$ and serum sodium levels among males $(\mathrm{r}=-0.640, \mathrm{p}=0.0001)$ and females $(\mathrm{r}=-0.732, \mathrm{p}=0.0001)$. A significant positive correlation was observed between $\mathrm{HbA1C}$ and serum potassium as well as chloride levels in males $(r=0.490, p=0.0001$ and $\mathrm{r}=0.248, \mathrm{p}=0.0001$, respectively) and females $(\mathrm{r}=0.522, \mathrm{p}=0.0001$ and $r=0.275, p=0.002$, respectively). However, we found no correlation between $\mathrm{HbA1C}$ and serum bicarbonate levels among males ( $\mathrm{r}=-0.053$, $\mathrm{p}=0.479)$ and females $(\mathrm{r}=-0.031, \mathrm{p}=0.74)$.

We also compared serum electrolyte levels between anemic and non-anemic individuals among diabetics and non-diabetics. Among diabetics, we found a significant lower serum sodium levels $(p=0.0001)$ and a significant higher serum potassium $(p=0.0001)$ and chloride $(\mathrm{p}<0.05)$ levels in anemic patients in comparison with non-anemic subjects. However, the serum bicarbonate level was found to be similar in both groups. Among non-diabetics, we observed no significant difference between anemic and non-anemic subjects for serum sodium, potassium, chloride, and bicarbonate levels $(\mathrm{p}>0.05)$.
In the present study, we observed that majority $67.4 \%(\mathrm{n}=101)$ of cases with $\mathrm{HbA1C}$ levels $\leq 7 \%$ had normal serum sodium levels. Most of the diabetic patients with $\mathrm{HbA1C}$ levels between 7.1 and $12.9 \%$ had mild hyponatremia and those with HbA1C levels $\geq 13 \%$ had severe hyponatremia. Hence, there was a statistically significant association between HbA1C levels and severity of hyponatremia $(\mathrm{p}=0.0001)$

\section{DISCUSSION}

DM is a metabolic disorder characterized by chronic hyperglycemia with defective carbohydrate and fat metabolism. These defects are mostly due to impaired insulin secretion from pancreatic $\beta$ cells and/or insulin resistance to the target cells such as skeletal muscles, liver, and adipose tissues [10]. Diabetic patients have a greater risk of developing a number of major health problems [11]. The incidence of diabetes is sharply increasing worldwide with many long-term macro- and micro-vascular complications $[12,13]$. The International Diabetes Federation reported that total number of diabetic subjects in India is 41 million in 2006 and that this would increase to 70 million by the year 2025 [14].

Electrolytes play a vital role in intermediary metabolism and cellular function, including enzyme activities and electrical gradients. The electrolytes in serum include sodium, potassium, chloride, and bicarbonate [15]. Electrolyte disorders in diabetes are usually multifactorial in nature. Various pathophysiological factors such as nutritional status, gastrointestinal absorption capacity, pharmacological agents, coexistent acid-base disorders, other comorbid diseases (especially, renal disease), and acute illness play a key role in electrolyte imbalance [5].

Electrolyte imbalance occurs in DM patients as a consequence of hyperglycemia, hyperosmolality, and acidosis [16]. The association between blood glucose and electrolytes is complex, and electrolyte imbalance may affect the course of DM and its management, due to which special interest is centered on their relationship.

Prevalence of anemia is DM is estimated about 10-30\% [17]. Several studies suggest that anemia is twice as common in diabetics compared with non-diabetics. Despite these facts, anemia is unrecognized in $25 \%$ of patients with diabetes $[18,19]$. Anemia also develops earlier and is more severe in patients with diabetes than in patients with renal impairment from other causes [20]. The etiology of anemia in diabetes is multifactorial and includes inflammation, nutritional deficiencies, autoimmune diseases, hormonal changes, drugs in addition to kidney disease [19]. Anemia is found to contribute to the development and progression of diabetic complications which has a negative impact on the quality of life and an additional burden on the health of these patients [20].

Diabetes as well as hyperglycemia has a direct association with the development of an inflammatory condition showed by the increase in pro-inflammatory cytokines such as IL- 6 and TNF- $\alpha$. Thus, diabetes, as well as hyperglycemia due to its nature, is also an inflammatory disease character. Studies show that the longer the duration of the disease and/ or loss of glycemic control, the higher the inflammatory process [21].

The elevation of pro-inflammatory cytokines plays an essential role in insulin resistance and induces the appearance of diabetic macrovascular (cardiovascular) and microvascular (diabetic retinopathy) complications, kidney disease, and anemia. By increasing, especially IL-6, antierythropoietic effect occurs, since this cytokine alters the sensitivity of progenitors to erythropoietin (erythroid growth factor) and also promotes apoptosis of immature erythrocytes causing a decrease, further, in the number of circulating erythrocytes and consequently causing a reduction of circulating hemoglobin [22].

Glycated hemoglobin (HbA1C) is widely used as a gold standard for monitoring glycemic control and also serves as a predictor of complications of diabetes. According to the ADA guidelines, the value 
of HbA1c should be kept below 7\% in all the diabetics [23]. To the best of our knowledge, no studies have been performed so far to investigate the relationship between serum electrolytes with HbA1C levels and $\mathrm{Hb}$ levels.

The present study has observed that electrolyte levels were altered in diabetic patients when compared with non-diabetic control subjects. Our study results (Table 1 and Fig. 1a) show a significant decrease in serum levels of sodium among diabetic patients, in comparison with non-diabetics, and this is in accordance with the study results of Al-Ajlan et al. and Saito et al. [24,25]. Our study contradicts with the results of Deepti et al. who found no significant variation in electrolyte levels between DM and non-DM [26]. Table 2 shows that as HbA1C increases, severity of hyponatremia worsens. In this study, we also demonstrated the significant negative correlation (Table 3 and Fig. 2a) of serum sodium with $\mathrm{HbA1C}$, which is consistent with the findings of Khalid et al., and Ugwuja E et al. $[27,28]$.

Several underlying mechanisms have been proposed for hyponatremia in DM. Liamis et al. suggested that glucose is an osmotically active substance. Hence, hyperglycemia increases serum osmolality which in turn results in movement of water out of the cells and subsequently in a reduction of serum sodium levels by dilution. It is worth mentioning that the corrected sodium levels after adjustment for the dilutional effect of hyperglycemia should be considered as a useful tool for monitoring the treatment in hyperglycemic states [29]. Totan and Greabu reported that $\mathrm{Na}^{+}-\mathrm{K}^{+}$-ATPase is a ubiquitous enzyme that ensures the maintenance of transmembrane gradients of sodium and potassium. Alterations of the transport enzyme are thought to be linked electrolyte abnormalities leading to several complications such as polyneuropathy of DM [30]. Drug-induced hyponatremia due to hypoglycemic agents such as chlorpropamide, insulin, tolbutamide, diuretics, and amitriptyline should be considered in every diabetic patient with low serum sodium levels [29].

Furthermore, we observed significantly higher levels of serum potassium in diabetic patients than non-diabetics (Table 1 and Fig. 1b). This result of ours coincides with the study results of Saito et al. and Al-Jameil [25,31]. Wang et al. reported only $0.6 \%$ of diabetes had hypokalemia and $12 \%$ of diabetes subjects had hyperkalemia [32]. However, this is in contrast to the study results of Ugwuja and Eze [28], who reported low serum potassium in diabetes than non-diabetics. In this study, we also demonstrated the significant positive correlation (Table 3 and Fig. 2 b) of serum potassium with HbA1C.
The incidence of hyperkalemia is higher in DM due to redistribution of potassium from the intracellular to the extracellular compartment (shift hyperkalemia) as occurs in acidosis, hypertonicity, insulin deficiency, and rhabdomyolysis. Liamis et al., in his studies, suggested that combination of insulin deficiency and hyperglycemia-induced hyperosmolality in DM would promote cellular dehydration, thus leading to an increase potassium efflux from the cell [29].

Serum levels of chloride (Table 1 and Fig. 1c) were significantly higher in diabetic patients compared to non-diabetics. This finding of ours agree with the study results of Julius and Kumar and Hasona and Elasbali [33,34], but controverts with Deepti et al. who reported no significant variation in chloride in diabetics compared to nondiabetics [26]. Table 3 and Fig. 2c clearly illustrate a significant positive correlation of serum chloride with HbA1C. DM a globally prevalent syndrome if not checked leads to life-threatening complications such as diabetic ketoacidosis [35]. Elevated serum chloride levels were found in DM, and this might be due to reduction in blood $\mathrm{pH}$ which occurs in ketoacidosis which further disturbs acid-base balance and results in elevation of serum chloride levels [31].

In our present study, we also compared serum electrolyte levels between anemic and non-anemic patients among diabetics and nondiabetics. We observed (Table 4) significantly lower serum sodium as well as higher potassium and chloride levels only in diabetic patients with anemia when compared with non-anemic subjects.

\section{Limitations of the study}

With this cross-sectional study design, we could not follow up and compare the electrolyte levels in diabetic patients after glucose control, the mechanism by which diabetes affects electrolyte levels was not evaluated, and finally, small sample size was some of the limitations of this study.

\section{CONCLUSION}

Our study provides an overview and advances our knowledge of imbalance in serum electrolyte levels and its association with increased HbA1C and hemoglobin levels among patients with Type 2 DM in comparison to non-diabetics. This insight should pave the way for pathophysiology-directed therapy, thus contributing to the avoidance of several deleterious effects associated with electrolyte disorders and their treatment in diabetes. Further multicenter research with large sample size is recommended for accurate assessment of association of diabetes and electrolyte imbalance.

Table 1: Comparison of HbA1C and electrolyte levels between diabetics and non-diabetic subjects

\begin{tabular}{lllll}
\hline Parameters & Diabetics $\mathbf{n = 1 5 0}$ (mean \pm SEM) & Non-diabetics n=150 (mean \pm SEM) & t-test & p value \\
\hline HbA1C (\%) & $10.82 \pm 0.19$ & $5.94 \pm 0.05$ & 25.409 & $0.0001^{* *}$ \\
Sodium (mmol/L) & $127.92 \pm 0.45$ & $135.82 \pm 0.34$ & -14.013 & $0.0001^{* *}$ \\
Potassium (mEq/L) & $4.66 \pm 0.05$ & $4.09 \pm 0.05$ & 7.918 & $0.0001^{* *}$ \\
Chloride (mEq/L) & $104.90 \pm 0.50$ & $102.15 \pm 0.45$ & 4.067 & $0.0001^{* *}$ \\
Bicarbonate (mEq/L) & $23.23 \pm 0.38$ & $23.82 \pm 0.33$ & -1.187 & 0.236 \\
\hline
\end{tabular}

Data were represented as mean \pm SEM and analyzed by student $t$-test between diabetics and non-diabetics. Significant $*$ p $<0.05$

Table 2: Relationship between serum sodium levels and grades of HbA1C levels

\begin{tabular}{|c|c|c|c|c|}
\hline \multirow[t]{2}{*}{ HbA1C \% } & \multicolumn{4}{|c|}{ Serum sodium (mmol/L) level } \\
\hline & $\begin{array}{l}\text { Normal } \\
135-145 \\
\mathrm{mmol} / \mathrm{n}(\%)\end{array}$ & $\begin{array}{l}\text { Mild hyponatremia } \\
\text { 130-134 } \\
\text { mmol/L n (\%) }\end{array}$ & $\begin{array}{l}\text { Moderate hyponatremia } \\
\text { 125-129 } \\
\text { mmol/L n (\%) }\end{array}$ & $\begin{array}{l}\text { Severe hyponatremia } \\
<125 \\
\text { mmol/L n (\%) }\end{array}$ \\
\hline$\leq 7(n=150)$ & $101(67.4)$ & $38(25.4)$ & $7(4.6)$ & $4(2.6)$ \\
\hline $7.1-8.9(\mathrm{n}=34)$ & $9(26.4)$ & $12(35.3)$ & $9(26.5)$ & $4(11.8)$ \\
\hline $9-10.9(n=53)$ & $12(22.6)$ & 17 (32.1) & $13(24.5)$ & $11(20.8)$ \\
\hline $11-12.9(n=33)$ & $5(15.2)$ & $5(15.2)$ & $11(33.3)$ & $12(36.4)$ \\
\hline $13-14.9(n=23)$ & $0(0)$ & $1(4.3)$ & $4(17.4)$ & $18(78.3)$ \\
\hline$\geq 15(\mathrm{n}=7)$ & $0(0)$ & $0(0)$ & $0(0)$ & $7(100)$ \\
\hline
\end{tabular}

Chi-square $-171.336, \mathrm{p}=0.0001$ 


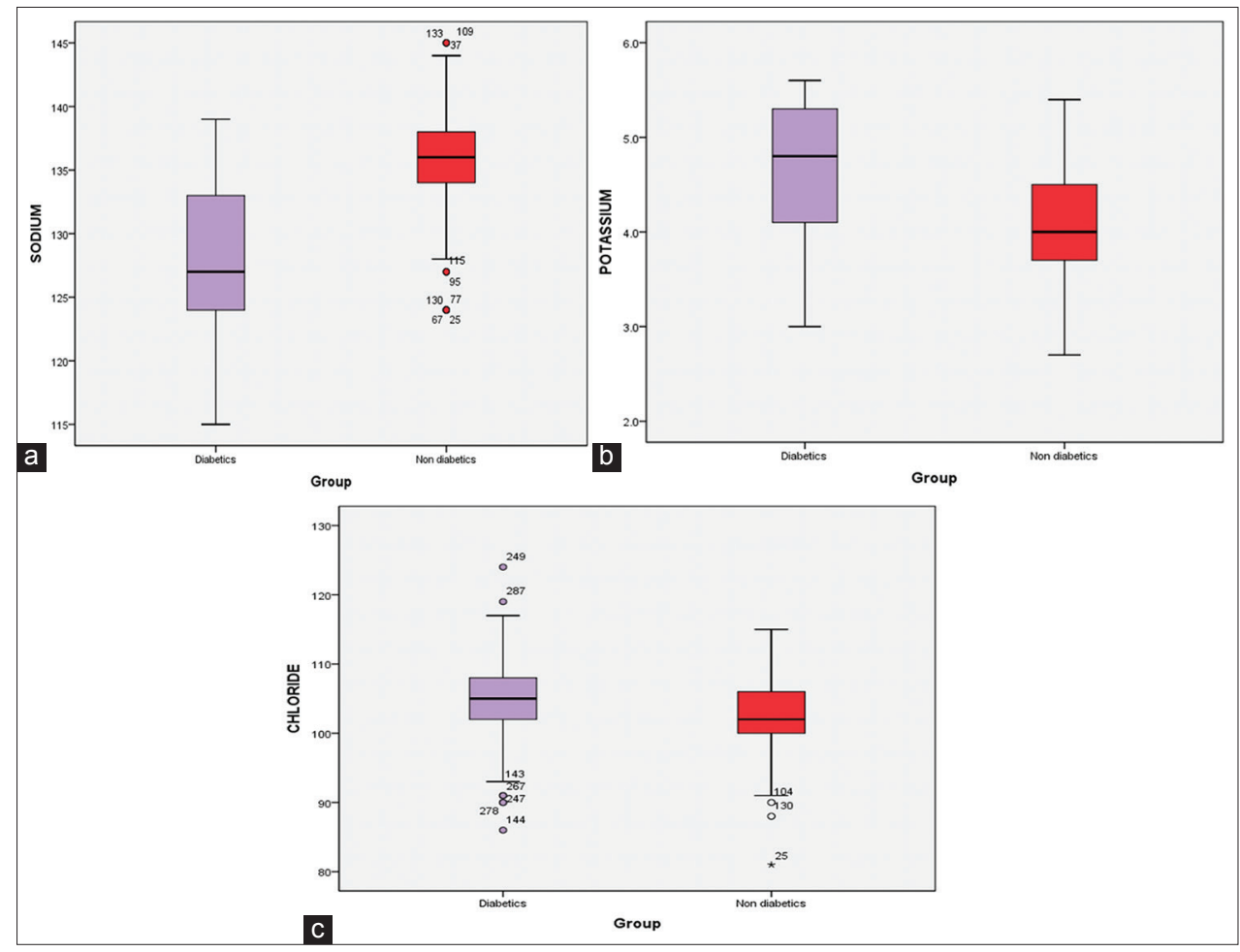

Fig. 1: Comparison of HbA1C and electrolyte levels between diabetics and non-diabetic subjects (a) serum sodium levels, (b) serum potassium levels, and (c) serum chloride levels
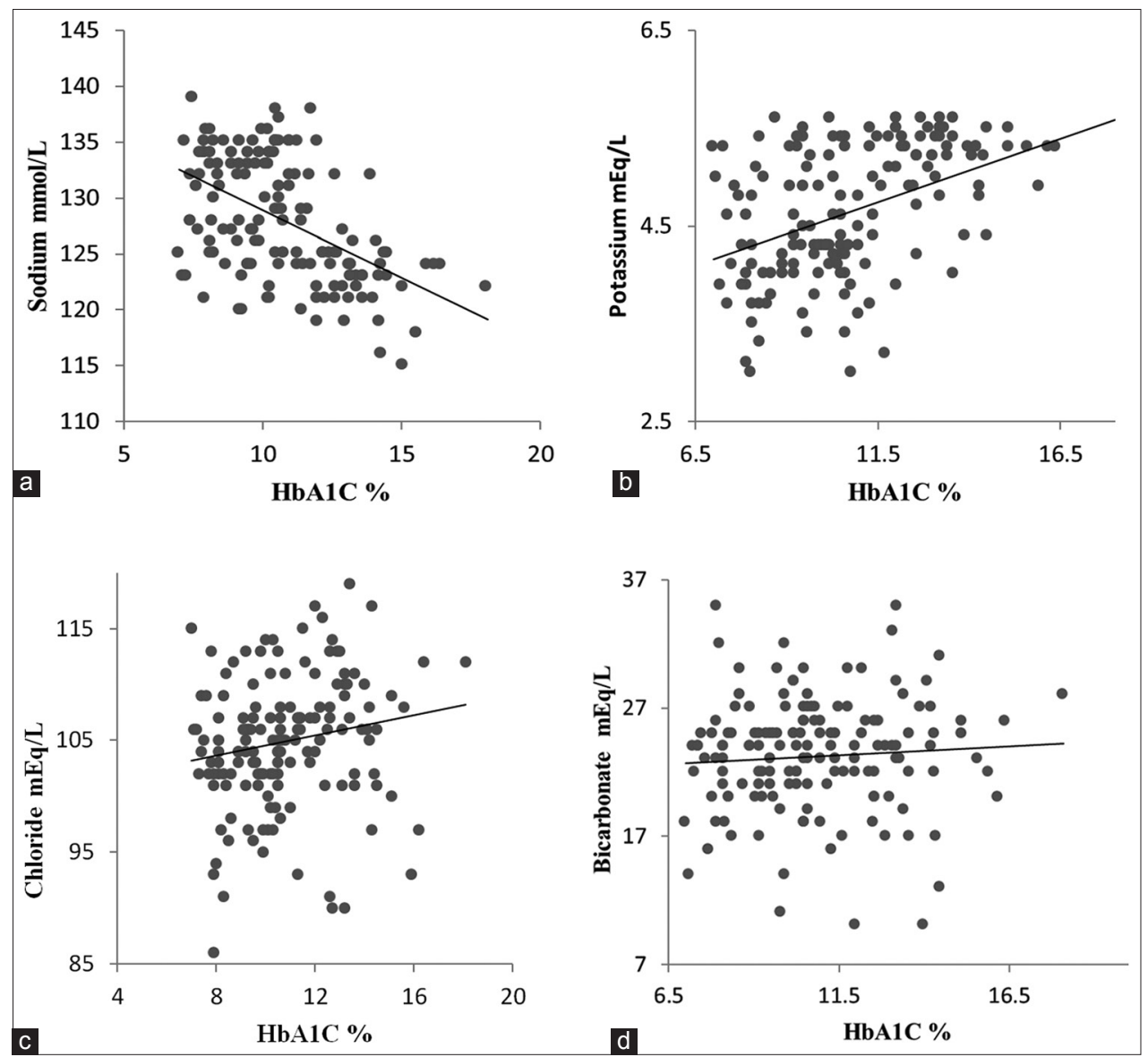

Fig. 2: Scatter plot representation of correlation between serum electrolytes and HbA1C levels (a) serum sodium and HbA1C levels, (b) serum potassium and HbA1C levels, (c) serum chloride and HbA1C levels, and (d) serum bicarbonate and HbA1C levels 
Table 3: Correlation between serum electrolytes and HbA1C levels among males and females

\begin{tabular}{lll}
\hline Gender & HbA1C & $\mathbf{p}$ \\
\cline { 2 - 3 } & $\mathbf{r}$ & $0.0001^{* *}$ \\
\hline Male (n=180) & & $0.0001^{* *}$ \\
$\quad$ Sodium & -0.640 & $0.001^{*}$ \\
Potassium & 0.490 & 0.479 \\
Chloride & 0.248 & $0.0001^{*}$ \\
$\quad$ Bicarbonate & -0.053 & $0.0001^{* *}$ \\
Female (n=120) & & $0.002^{*}$ \\
Sodium & -0.732 & 0.740 \\
Potassium & 0.522 & 0.275 \\
Chloride & -0.031 & \\
Bicarbonate & & \\
\hline
\end{tabular}

${ }^{*}$ Significant $(\mathrm{p}<0.05),{ }^{* *}$ Highly significant $(\mathrm{p}=0.0001)$

Table 4: Comparison of electrolyte levels between anemic and non-anemic individuals among diabetics and non-diabetics

\begin{tabular}{|c|c|c|c|c|c|}
\hline Parameters & $\mathbf{n}$ & $\begin{array}{l}\text { Sodium }(\mathrm{mmol} / \mathrm{L}) \\
(\mathrm{mean} \pm \mathrm{SEM})\end{array}$ & $\begin{array}{l}\text { Potassium }(\mathrm{mEq} / \mathrm{L}) \\
(\text { mean } \pm \text { SEM) }\end{array}$ & $\begin{array}{l}\text { Chloride }(\mathrm{mEq} / \mathrm{L}) \\
(\text { mean } \pm \text { SEM) }\end{array}$ & $\begin{array}{l}\text { Bicarbonate }(\mathrm{mEq} / \mathrm{L}) \\
(\mathrm{mean} \pm \mathrm{SEM})\end{array}$ \\
\hline \multicolumn{6}{|l|}{$\mathrm{DM}$} \\
\hline Anemia & 90 & $125.44 \pm 0.53$ & $4.95 \pm 0.06$ & $105.79 \pm 0.65$ & $22.91 \pm 0.53$ \\
\hline Non-anemic & 60 & $131.63 \pm 0.50$ & $4.22 \pm 0.07$ & $103.57 \pm 0.76$ & $23.70 \pm 0.50$ \\
\hline t-test & & -8.108 & 7.677 & 2.196 & -1.023 \\
\hline $\mathrm{p}$ value & & $0.0001^{* *}$ & $0.0001^{* *}$ & $0.03^{*}$ & 0.308 \\
\hline \multicolumn{6}{|l|}{ Non-DM } \\
\hline Non-anemic & 77 & $135.94 \pm 0.44$ & $4.13 \pm 0.06$ & $101.83 \pm 0.55$ & $23.55 \pm 0.48$ \\
\hline t-test & & -0.344 & -0.793 & 0.712 & 0.860 \\
\hline $\mathrm{p}$ value & & 0.731 & 0.429 & 0.477 & 0.391 \\
\hline
\end{tabular}

Data were represented as mean \pm SEM and analyzed by student t-test between diabetics and non-diabetics. Significant * $p<0.05$

\section{ACKNOWLEDGMENT}

The authors would like to express my heartfelt thanks to our Dean Dr.A.Sundaram, SRM Medical College Hospital and Research Centre for his support throughout the study. The authors thankful to all the participating people for their cooperation.

\section{REFERENCES}

1. Sarkar A, Dash S, Barik BK, Muttigi MS, Kedage V, Shetty JK, et al. Copper and ceruloplasmin levels in relation to total thiols and GST in Type 2 diabetes mellitus patients. Indian J Clin Biochem 2010;25:74-6.

2. Rajagopal L, Ganapathy S, Arunachalam S, Raja V, Ramraj B. Does iron deficiency anaemia and its severity influence $\mathrm{HbA} 1 \mathrm{C}$ level in non diabetics? An analysis of 150 cases. J Clin Diagn Res 2017;11:EC13.

3. Wannamethee G, Whincup PH, Shaper AG, Lever AF. Serum sodium concentration and risk of stroke in middle-aged males. J Hypertens 1994;12:971-9.

4. Al-Rubeaan K, Siddiqui K, Abu Risheh K, Hamsirani R, Alzekri A, Alaseem A, et al. Correlation between serum electrolytes and fasting glucose and $\mathrm{Hb} 1 \mathrm{Ac}$ in Saudi diabetic patients. Biol Trace Elem Res 2011;144:463-8

5. Elisaf MS, Tsatsoulis AA, Katopodis KP, Siamopoulos KC. Acid-base and electrolyte disturbances in patients with diabetic ketoacidosis. Diabetes Res Clin Pract 1996;34:23-7.

6. Kaur M, Singh A, Bassi R, Kaur H. Nutritional status and anaemia in medical students of SGRDIMSAR, Amritsar. Natl J Physiol Pharm Pharmacol 2015;5:45-9.

7. Hosseini MS, Rostami Z, Saadat A, Saadatmand SM, Naeimi E. Anemia and microvascular complications in patients with Type 2 diabetes mellitus. Nephrourol Mon 2014;6:e19976.

8. Cawood TJ, Buckley U, Murray A, Corbett M, Dillon D, Goodwin B, et al. Prevalence of anaemia in patients with diabetes mellitus. Ir J Med Sci 2006; 175:259.

9. Tannen RL. Potassium disorders. In: Kokko JP, Tannen RL, editors. Fluids and Electrolytes. $2^{\text {nd }}$ ed. Philadelphia, PA: WB Saunders Co.; 1990. p. 195-300.

10. Kalsi A, Singh S, Taneja N, Kukal S, Mani S. Current treatment for Type 2 diabetes, their side effects and possible complementary treatments. Int J Pharm Pharm Sci 2015;3:13-8.

11. Haghighatpanah M, Thunga G, Khare S, Mallayasamy S. Correlation of glycosylated hemoglobin levels with fasting and postprandial glucose in south Indian Type 2 diabetic patients. Int J Pharm Pharm Sci 2016;8:285-8

12. Kilpatrick ES, Bloomgarden ZT, Zimmet PZ. Is haemoglobin A1c a step forward for diagnosing diabetes? BMJ 2009;339:b4432.

13. Rajagopal L, Arunachalam S, Ganapathy S, Ramraj B. Impact of iron deficiency anemia on glycated hemoglobin (HbAlc) levels in diabetics with controlled plasma glucose levels. Ann Pathol Lab Med 2017;4:A148-52

14. Sicree R, Shaw J, Zimmet P. Diabetes and impaired glucose tolerance. In: Gan D, editor. Diabetes Atlas: International Diabetes Federation. $3^{\text {rd }}$ ed., Vol. 15. Belgium: International Diabetes Federation; 2006. p. 103.

15. Lobo DN. Fluid, electrolytes and nutrition: Physiological and clinical aspects. Proc Nutr Soc 2004;63:453-66.

16. Yawar A, Jabbar A, Haque NU, Zuberi LM, Islam N, Akhtar J. Hyponatraemia: Etiology, management and outcome. J Coll Physicians Surg Pak 2008;18:467-71.

17. Hosseini MS, Rostami Z, Saadat A, Saadatmand SM, Naeim E. Anemia and microvascular complications in patients with Type 2 diabetes mellitus. Nephrourol Mon 2014;6:e19976.

18. Wright JA, Oddy MJ, Richards T. Presence and characterisation of anaemia in diabetic foot ulceration. Anemia 2014;2014:104214.

19. Abate A, Birhan W, Alemu A. Association of anemia and renal function test among diabetes mellitus patients attending Fenote Selam hospital, West Gojam, Northwest Ethiopia: A cross sectional study. BMC Hematol 2013;13:6.

20. Thomas MC, Cooper ME, Rossing K, Parving HH. Anaemia in diabetes: Is there a rationale to TREAT? Diabetologia 2006;49:1151-7.

21. Angelousi A, Larger E. Anaemia, a common but often unrecognized risk in diabetic patients: A review. Diabetes Metab 2015;41:18-27.

22. Fava S, Azzopardi J, Ellard S, Hattersley AT. ACE gene polymorphism as a prognostic indicator in patients with Type 2 diabetes and established renal disease. Diabetes Care 2001;24:2115-20.

23. Mayer TK, Freedman ZR. Protein glycosylation in diabetes mellitus: A review of the laboratory measurements and of their clinical utilities. Clin Chim Acta 1983;127:147e-84.

24. Al Ajlan AR. Incidence of hyperkalemia in patients of Type 1 and Type 2 diabetes mellitus in Saudi Arabia. Middle East J Fam Med 2007;5:27-9

25. Saito T, Ishikawa S, Higashiyama M, Nakamura T, Rokkaku K, 
Hayashi $\mathrm{H}$, et al. Inverse distribution of serum sodium and potassium in uncontrolled inpatients with diabetes mellitus. Endocr J 1999;46:75-80.

26. Deepti GN, Cherian S, Lakshmi K. A comparative study of electrolyte imbalances in controlled and uncontrolled diabetes mellitus. Int J Clin Biochem Res 2017;4:22-4

27. Khalid R, Khalid S, Khaled AR, Roderick H, Abdul M, Khalid A. Correlation between serum electrolytes and fasting glucose and $\mathrm{Hb} 1 \mathrm{Ac}$ in Saudi diabetic patients. Biol Trace Elem Res 2011;144:463-8.

28. Ugwuja E, Eze N. A comparative study of serum electrolytes, total protein, calcium and phosphate among diabetic and HIV/AIDS patients in Abakaliki, Southeastern, Nigeria. Internet J Lab Med 2006;2:14.

29. Liamis G, Liberopoulos E, Barkas F, Elisaf M. Diabetes mellitus and electrolyte disorders. World J Clin Cases 2014;2:488.

30. Totan AR, Greabu M. Effect of chronic hyperglycemia and vanadate treatment on erythrocyte $\mathrm{Na} / \mathrm{K}$-ATpase and Mg-ATpase in streptozotocin diabetic rats. Acta Pol Pharm 2002;59:307-11.

31. Al-Jameil N. Estimation of serum electrolytes in diabetes patients of Saudi region. Life Sci J 2014;11:378-80.

32. Wang S, Xuhong H, Yu L, Huijuan L, Li W, Yuquian B, et al. Serum electrolytes relation to macrovascular complications in Chinese patients with diabetes mellitus. Cardiovasc Diabetetol 2013;12:146-55.

33. Julius A, Kumar JP, Chidambaram R, Kumar RS, Deepa M. Evaluation of glycosylated hemoglobin and electrolyte status in diabetic ketoacidosis. Int J Clin Biomed Res 2015;1:87-9.

34. Hasona NA, Elasbali A. Evaluation of electrolytes imbalance and dyslipidemia in diabetic patients. Med Sci 2016;4:7.

35. Paul D, Paul K. Diabetes mellitus and its complications: A review. Int J Curr Pharm Res 2012;4:12-7. 